\title{
Making of Natural Dyeing Scarves by Tie-Dyeing Technique
}

\author{
Jin Soun Jung \\ Major of Fashion Culture Design, School of Convergence Design, Semyung University, Jecheon, South Korea
}

\begin{abstract}
This research aims to make a natural and eco-friendly scarves of Korean and modern style. For the purpose, natural dyeing with safflower, sappan wood, gromwell, amur cork, and areca nut was carried out. As a result, traditional multi-colored scarves were created. And unique scarves of patterns were made by various tie-dyeing methods like tying, folding, wrapping, pleating, and twisting.
\end{abstract}

\section{Introduction}

Natural dyes obtained from plants, insects/animals and minerals, are renewable and sustainable bio resource products with minimum environmental impact and known since antiquity for their use, not only as food ingredients [1] and cosmetics [2] but also in textile colouration [3]. Natural dyes have also been used for printing and dye-sensititized solar cells [4]. It is reported that some natural dyes not only dye with unique and elegant colors, but also provide antibacterial, deodorizing and UV protective functions to fabrics [5]. With the level of interest rising about accessory today, scarf get out of ancilary role of clothes and its proportion is gradually expending to a leading position where it leads the overall atmosphere of fashion. But as Korean scarf design is not getting away from the mimic stage to foreign brand, Koreans should develop their own creative scarf design now. It needs to develop scarf design of Korean and modern style through natural dyeing using tie-dyeing technique. Therefore the purpose of this study is to make a natural and eco-friendly scarves by various tie-dyeing methods using natural materials such as safflower, sappan wood, gromwell, amur cork, and areca nut.

\section{Theoretical background}

\subsection{Safflower}

Safflower (Carthamus tinctorius L.), which is an annual plant of chrysanthemum, contains yellow and red pigments (carthamin) in its petal. The safflower pigments have been traditionally used in cloth dyeing and natural cosmetic material as early as $4500 \mathrm{BC}$. The yellow dyestuff (water-soluble) was used for dyeing mordanted wool and silk while the red dyestuff (water-unsoluble) was used as a direct dye, i.e. without mordanting, or as a red organic pigment for painting purposes [6]. Carthamin is the major red pigment in safflower and it has antioxidant activity [7]. The basic structure of those pigments is a C-glucosyl quinochalcone [8]. Figure 1 showed the chemical structure of carthamin contained in safflower.<smiles>O=C(/C=C/c1ccc(O)cc1)C1=C(O)C(O)(Cl)C(O)(Cl)C(O)(O)C1=O</smiles>

Figure 1. Chemical structure of carthamin contained in safflower

\subsection{Sappan wood}

Caesalpinia sappan L. is a plant of Leguminosae family, commonly known as Brazil or Sappan wood. Caesalpinia sappan L. (Leguminosae) is distributed in Southeast Asia. Brazilin is the major compound naturally occurring in the Caesalpinia sappan L. heartwood and is used as a red dye for histological staining [9]. In traditional Chinese medicine, brazilin is used for treatment of increased blood circulation, promotes menstruation and exhibit analgesic and anti-inflammatory potentials [10]. Figure 2 showed the chemical structure of brazilin contained in sappan wood.

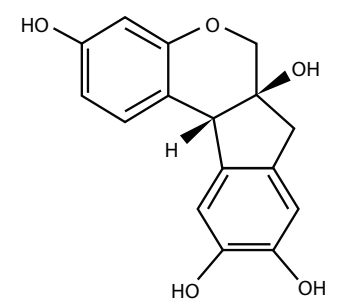

Figure 2. Chemical Structure of brazilin contained in sappan wood 


\subsection{Gromwell}

Lithospermum erythrorhizon Sieb. et Zucc. has been used traditionally as medicine in China and as a dye for staining fabrics and food colorants [11]. The roots of Lithospermum erythrorhizon Sieb. et Zucc. accumulate shikonin derivatives, which are red naphthoquinone pigments. Shikonin, a naphthoquinone pigment, has been used in traditional Chinese medicines for thousands of years. Figure 3 showed the chemical structure of shikonin contained in gromwell.<smiles>CC(C)=CCC(O)C1=CC(=O)c2c(O)ccc(O)c2C1=O</smiles>

Figure 3. Chemical structure of shikonin contained in gromwell

\subsection{Amur cork}

Phellodendron amurense Rupr is an important associated species in the forest, in Northeast China, and also a pharmaceutical resource plant for its phloem, a Chinese traditional medicine [12]. Phellodendron amurense Rupr contains a number of alkaloids such as berberine, palmatine, phellodendrine etc [13], and used as antiinflammatory agent, promoting blood circulation, dysentery, diuretic, hemorrhage and blood glucose regulating etc [14]. Figure 4 showed the chemical structure of berberine contained in amur cork.<smiles>COc1ccc2cc3[n+](cc2c1OC)CCc1cc2c(cc1-3)OCO2</smiles>

Figure 4. Chemical structure of berberine contained in amur cork

\subsection{Areca nut}

A. catechu Linn. commonly known as betel nut, a slender palm from Arecaceae family, which is widely distributed in south-east Asia and India in coastal regions of Maharashtra to Kerala and Tamil Nadu. The nuts of $A$. catechu exhibits multiple therapeutic properties. Areca nut largely contains sugars, lipids and polyphenols [15]. Polyphenols in areca nut comprise of condensed tannins, hydrolysable tannins, and flavonols. Polyphenols are the most bio-active components of areca nut. Figure 5 showed the chemical structure of catechuins contained in areca nuts.<smiles>OC1CC(O)C2CC(O)C3(CCC(O)C(O)C3)OC2C1</smiles>

Figure 5. Chemical structure of catechin contained in areca nuts

\section{Materials and methods of tie and dyeing}

\subsection{Materials}

\subsubsection{Natural materials}

The plant materials such as safflower, sappan wood, gromwell, amur cork and areca nut were purchased from traditional medical herb market at Jecheon.

\subsubsection{Fabrics for scarves}

Satins and chiffons of $100 \%$ silk were used for scarves.

\subsubsection{Mordants and reagents}

Ferrous sulfate, copper sulphate, aluminium acetate, ethanol, potassium carbonate, and acetate acid etc was used first-class goods on the market.

\subsection{Methods of tie dyeing}

\subsubsection{Tie methods}

The tie-methods $[16,17]$ used in this study were shown in Table 1.

Table 1. The tie methods

\begin{tabular}{|c|l|}
\hline \multicolumn{1}{|c|}{ The tie methods } \\
\hline 1 & $\begin{array}{l}\text { Grab the center of the fabric and tie it. } \\
\text { By varying the number of ties or } \\
\text { intervals, it is possible to make a variety } \\
\text { of tie expression. }\end{array}$ \\
\hline 2 & $\begin{array}{l}\text { After broad stitching the fabric with a } \\
\text { round circle, pull carefully the threads } \\
\text { and wrap the part three times with the } \\
\text { pulled thread. Then wrap the thread up at } \\
3 \sim 5 m m \text { intervals and rewind it to make the } \\
\text { knot. }\end{array}$ \\
\hline 3 & $\begin{array}{l}\text { Tie a small portion of the fabric with } \\
\text { thread or the like. }\end{array}$ \\
\hline 4 & $\begin{array}{l}\text { Put objects such as coins and beads in } \\
\text { fabric and tie them with thread. }\end{array}$ \\
\hline 5 & $\begin{array}{l}\text { First fold the fabric into folding screen. } \\
\text { Then tie it with thread. }\end{array}$ \\
\hline 6 & $\begin{array}{l}\text { Grasp both ends of the fabric and braid, } \\
\text { then tie the twisted fabric with thread or } \\
\text { rubber band. }\end{array}$ \\
\hline 7 & $\begin{array}{l}\text { Grab both ends of the fabric and braid, } \\
\text { then tie with thread in the middle. } \\
\text { then knot. At this time, put wooden bar } \\
\text { after dyeing. }\end{array}$ \\
\hline & $\begin{array}{l}\text { Fold the fabric into folding screen and } \\
\text { andily untie the knot }\end{array}$ \\
\hline
\end{tabular}




\begin{tabular}{|c|l|}
\hline 9 & $\begin{array}{l}\text { After the fabric is crumpled, sew the } \\
\text { crumpled part, pull tightly and then tie } \\
\text { up. }\end{array}$ \\
\hline 10 & $\begin{array}{l}\text { Wrap the fabric and tie it with thread so } \\
\text { that it does not loosen. }\end{array}$ \\
\hline
\end{tabular}

\subsubsection{Dyeing methods}

\section{Safflower dyeing}

Extraction: In order to extract the yellow color of the safflowers, the flowers were soaked in 20 times of water for 24 hours. Rinsed with water while changing water several times. This process was repeated until removing of yellow water. Poured the $1 \%$ solution of potassium carbonate $(\mathrm{pH} 10.8) \mathrm{kept}$ at about $30^{\circ} \mathrm{C}$ into the vivid red safflowers that yellow colors were removed and rub for 20 minutes. Put them in the bag and squeezed them. Repeated this four times. The first extract was discarded. The 2nd to 4th extracts were collected and used as the red coloring extract.

Dyeing Method: The red pigment extracts obtained by extracting with $1 \%$ potassium carbonate solution were added with warm water of 10 times the amount of the extract to reach $\mathrm{pH} 7.5$ with $1 \%$ acetic acid and it was used as a solution for dyeing. The tied fabric was dyed for 20 minutes while maintaining the temperature of dye solution at 40 to $45^{\circ} \mathrm{C}$.

\section{Sappan wood dyeing}

Extraction of natural dyes: Sappan woods were soaked in the 20 times of water, heated and extracted for 60 minutes, and filtered. This process was repeated two times. The first and second extracts were combined and used as a solution for dyeing.

Dyeing Procedure: Fabrics were dyed at $90^{\circ} \mathrm{C}$ for $30 \mathrm{~min}$. while maintaining a bath ratio 1:50. The dyed fabrics were then washed and air dried. In the case of mordanting, postmordanting was carried out using $0.1 \%$ copper sulphate $\left(w / w\right.$ with respect to the fabric) at $40^{\circ} \mathrm{C}$ for $10 \mathrm{~min}$. The postmordanted fabrics were squeezed, washed and air dried.

\section{Gromwell dyeing}

Extraction of natural dyes: Gromwells were soaked in the 20 times of ethanol, heated and extracted at room temperature for 24 hours, and filtered. the filtered solution was diluted with the 5 times of water and it was used as a solution of dyeing.

Dyeing Procedure: Fabrics were dyed at room temperature for 30min. while keeping a bath ratio 1:50. The dyed fabrics were then washed and air dried. In the case of mordanting, premordanting was taken with $0.1 \%$ aluminium acetate at room temperature for $10 \mathrm{~min}$. The fabrics premordanted were squeezed, washed and air dried.

\section{Amur cork dyeing}

Extraction of natural dyes: Amur corks were soaked in the 20 times of water, heated and extracted for 60 minutes, and filtered. This process was repeated two times. The first and second extracts were combined and used as a solution for dyeing.

Dyeing Procedure: Fabrics were dyed at $90^{\circ} \mathrm{C}$ for $30 \mathrm{~min}$. while remaining a bath ratio 1:50. The dyed fabrics were then washed and air dried. In the case of mordanting, postmordanting was carried out with $0.1 \%$ ferrous sulfate( $\mathrm{Fe})$ at $40{ }^{\circ} \mathrm{C}$ for $10 \mathrm{~min}$. The postmordanted fabrics were squeezed, washed and air dried.

\section{Areca nut dyeing}

Extraction of natural dyes: Areca nuts were soaked in the 20 times of water, heated and extracted for 60 minutes, and filtered. This process was repeated two times. The first and second extracts were combined and used as a solution for dyeing.

Dyeing Procedure: Fabrics were dyed at $90^{\circ} \mathrm{C}$ for $30 \mathrm{~min}$. while maintaining a bath ratio 1:50. The dyed fabrics were then washed and air dried. In the case of mordanting, postmordanting was carried out using $0.1 \%$ ferrous sulfate $(\mathrm{Fe})$ at $40^{\circ} \mathrm{C}$ for $10 \mathrm{~min}$. The postmordanted fabrics were squeezed, washed and air dried.

\section{The natural dyeing scarves dyed by tie dyeing technique}

\subsection{Making of the work 1}

a. Takes a $90 \times 90 \mathrm{~cm}$ square of white silk fabric of satin and mark some circles on the fabric using water soluble pen.

b. Take and pull the center of each circle, then tie tightly each part indicated with rubber band.

c. Yellow was dyed with amur cork, red was dyed with sappan wood and, deep red was post-mordanted with copper sulphate after dyeing with sappan wood(work 1).

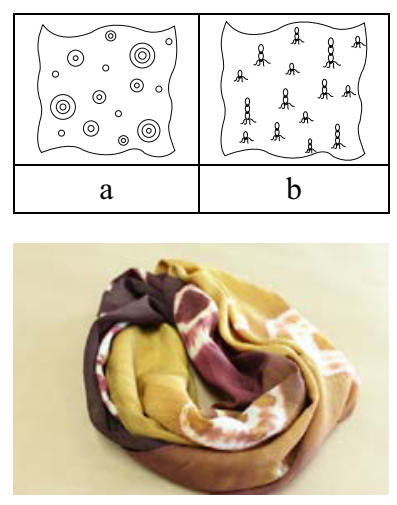

Work 1

4.2 Making of the work 2 
a. Takes a $90 \times 130 \mathrm{~cm}$ square of white silk fabric of chiffon.

b. Fold the fabric into folding screen.

c. The center of the folded fabric is knotted. At this time, put wooden bar between the knots, to easily untie the knot after dyeing. And bind tightly both the end of fabric with rubber bands.

d. Wrap firmly between the knots and the bound end. Secure with a knot.

e. Yellow was dyed with amur cork, brown was dyed with areca nut and, khaki was post-mordanted with ferrous sulfate after dyeing with amur cork(work 2).
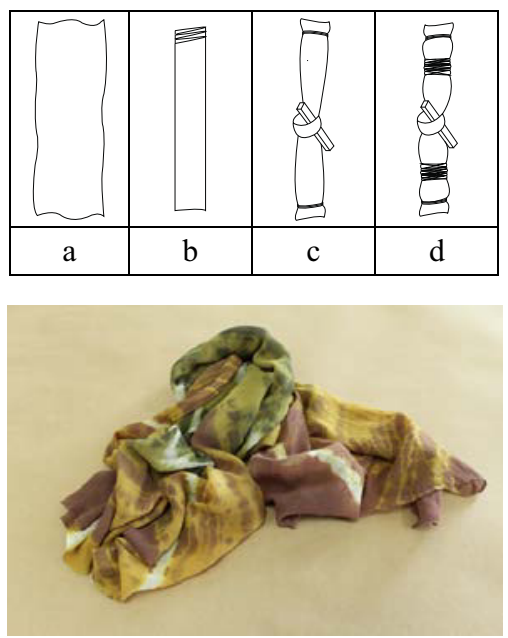

Work 2

\subsection{Making of the work 3}

a. Takes a $90 \times 130 \mathrm{~cm}$ square of white silk fabric of chiffon and, mark dots on the fabric with water soluble pen.

b. Put coins on the back of the marked spot.

c. Tie them with rubber bands.

d. Khaki was post-mordanted with ferrous sulfate after dyeing with amur cork and gray was post-mordanted with ferrous sulfate after dyeing with areca nut(work 3 ).
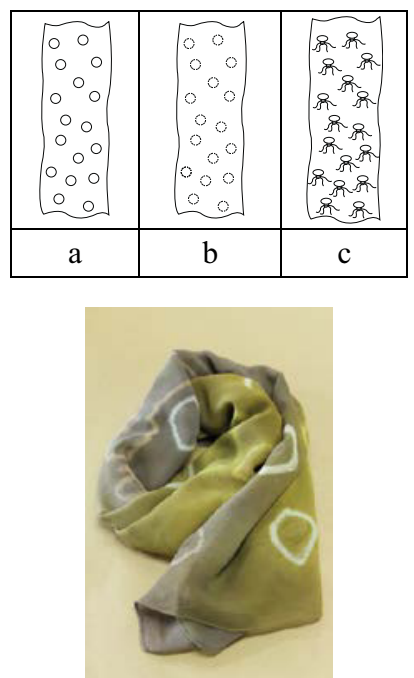

Work 3

\subsection{Making of the work 4}

a. Takes a $90 \times 130 \mathrm{~cm}$ square of white silk fabric of chiffon.

b. Fold the fabric into folding screen.

c. Braid it, then tie with rubber bands in the middle.

d. Brown was dyed with areca nut and gray was postmordanted with ferrous sulfate after dyeing with areca nut(work 4).
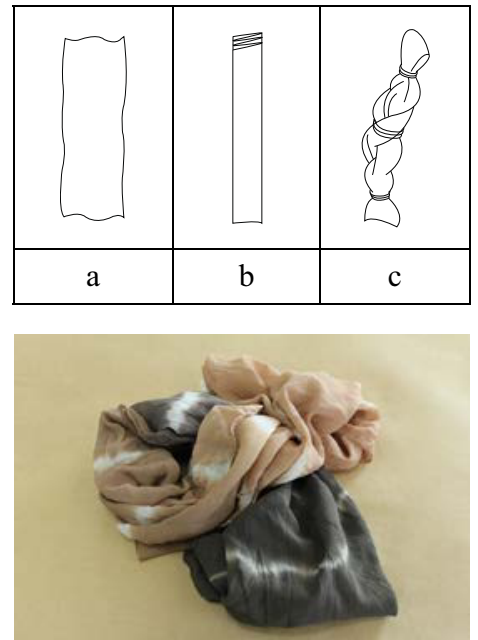

Work 4

\subsection{Making of the work 5}

a. Takes a $90 \times 90 \mathrm{~cm}$ square of white silk fabric of satin and mark some circles on the fabric using water soluble pen.

b. Broad stitch the marked place using a double thread in needle. After broad stitching, cut leaving at least $30 \sim 50 \mathrm{~cm}$ of thread.

c. After broad stitching the fabric with a round circle, pull carefully the threads and wrap the part three times with the pulled thread. Then wrap the thread up at $3 \sim 5 \mathrm{~mm}$ intervals and rewind it to make the knot.

d. Brown was dyed with areca nut and gray was postmordanted with ferrous sulfate after dyeing with areca nut(work 5).
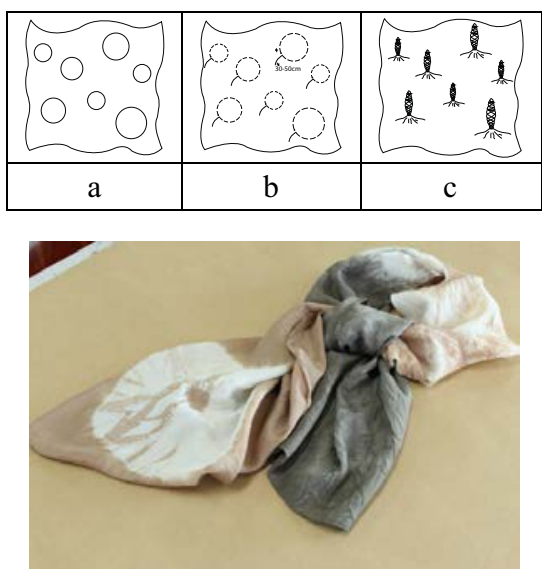

Work 5 


\subsection{Making of the work 6}

a. Takes a $90 \times 90 \mathrm{~cm}$ square of white silk fabric of satin.

b. Wrap the fabric.

c-d. Sew the crumpled part, pull tightly and then tie up. e. Pink was dyed with safflower and purple was dyed with gromwell after pre-mordanting with aluminium acetate(work 6).
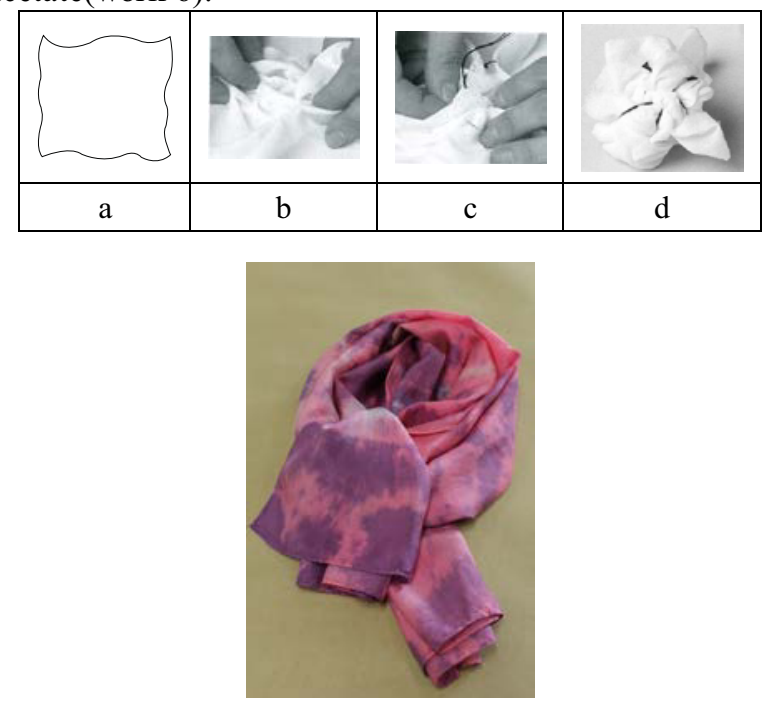

Work 6

\subsection{Making of the work 7}

a. Takes a $90 \times 90 \mathrm{~cm}$ square of white silk fabric of satin.

b. Crumple the fabric and bind the crumpled fabric with thread.

c. Purple was dyed with gromwell after pre-mordanting with aluminium acetate(work 7).
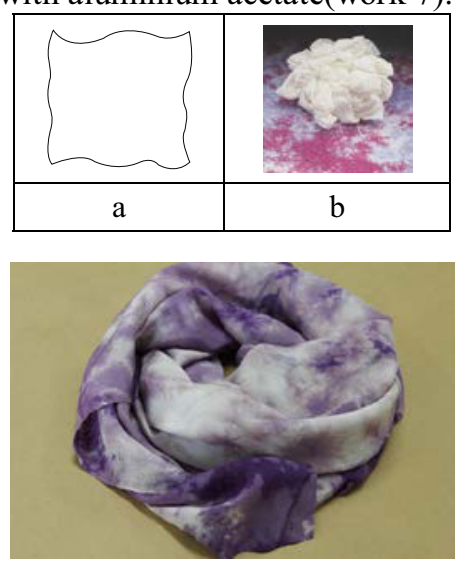

Work 7

\section{Conclusion}

In this study, seven eco - friendly scarves were made with natural materials such as safflower, sappan wood, gromwell, amur cork, and areca nut using various tiedyeing methods. Safflower was used to dye pink. Sappan wood was provided for red. Gromwell was supplied for purple. And Areca nut was used to dye brown. Also colorful scarves were able to make using aluminum, copper and iron mordant. The soft and natural scarves could be made through natural dyeing.

Acknowledgement: This paper is the product of research that was carried out the support of campus academic research funds of Semyung university in 2015.

\section{References}

1. A.C. Dweck, Int. J. Cosmet. Sci., 24, 287-302 (2002).

2. D. Frick, The coloration of food. Rev. Prog. Color, 33, 15-32 (2003).

3. S.J. Kadolph, Delta Kappa Gamma Bull., 75, 14-17 (2008).

4. K. Wongcharee, V. Meeyoo, S. Chavadej, Sol. Energy Mater. Sol. Cells, 91, 566-571 (2007).

5. D. Grifoni, L. Bacci, G. Zipoli, L. Albanese, F. Sabatini, Dyes Pigm., 91, 279-285 (2011).

6. Hofenk de Graaf JH., The colorful past: origins, chemistry and identification of natural dyestuff, London: Archetype Publications, (2004).

7. Y. Takahashi, N. Miyasaka, S. Tasaka, I. Miura, S. Urano, M. Ikura, et al., Tetrahedron Lett., 23, 51635166 (1982).

8. Y. Jin, X.L. Zhang, H. Shi, Y.S. Xiao, Y.X. Ke, X.Y. Xue, et al., Rapid Commun. Mass Spectrom., 22, 1275-1287 (2008).

9. I.K. Bae, H.Y. Min, A.R. Han, E.K. Seo, S.K. Lee, Eur. J. Pharmacol., 513, 3, 237-242 (2005).

10. China Pharmacopoeia Commission, The Chinese pharmacopoeia, Beijing: China Medical Science Press, (2010).

11. M. H. Cho, Y. S. Paik \& T. R. Hahn, J. Agric. Food Chem., 47, 4117-4120 (1999).

12. X. Li, Y. Wang, X. Yan, Acta Ecol. Sin., 27, 1, 5864 (2007).

13. Y.M. Lee, H. Kim, E.K. Hong, B.H. Kang, S.J. Kim, J. Ethnopharmacol., 73, 429-436 (2000).

14. H. Yan, X.D. Sun, S.G. Sun, S.H. Wang, J. Zhang, R. Wang, P. An, F. Yang, W. Kang, Int. J. Biol. Macromol, 48, 720-725 (2011).

15. P. Wetwitayaklung, T. Phaechamud, C. Limmatvapirat, S. Keokitichai, Naresuan Univ. J., 14, 1-14 (2006).

16. Kyoto University Art and Design, Learn how to dye, Kadokawa Shoten, (1998).

17. Library of Congress Cataloging-in-Publication Data, Exploring Textile Arts, Creative Publishing international, (2002). 